\title{
Una risa en el desierto: el arte de la resurrección y sermonesyprédicas del Cristo de Elqui*
}

Fecha de recepción: 02 de octubre de 2014

Fecha de aprobación: 18 de febrero de 2015

\section{Resumen}

En este artículo de reflexión se analiza la propuesta carnavalesca de la novela El arte de la resurrección (2010), de Hernán Rivera Letelier, y los poemarios Sermones y prédicas del Cristo de Elqui (1977) y Nuevos sermones y prédicas del Cristo de Elqui (1979), de Nicanor Parra. En estas obras interviene como protagonista un excéntrico predicador de existencia real en la historia de Chile: Domingo Zárate Vega, mejor conocido como el Cristo de Elqui. Se retoman planteamientos teóricos de Mijail Bajtín para explorar la risa y la locura como recursos estéticos que generan una visión crítica sobre la miseria de los mineros en las salitreras del desierto chileno, la dictadura militar de Augusto Pinochet y La matanza de la Escuela Santa María de Iquique (21 de diciembre de 1907).

Palabras Clave: Cristo de Elqui, antipoesía, narrativa chilena, carnaval, historia.

*Artículo de reflexión.

Citar: Gaitán Bayona, J.L. (julio-diciembre de 2015). Una risa en el decierto: el arte de la resurección y sermones y prédicas del Cristo de Elqui. La Palabra, (27), 159-170.
Jorge Ladino Gaitán Bayona

Universidad del Tolima,

Colombia

jlgaitan@ut.edu.co

Doctor en Literatura de la Pontificia Universidad Católica de Chile. Licenciado en Lenguas Modernas de la Universidad del Tolima. Profesor asociado de la Universidad del Tolima. Autor de los libros de poemas Manicomio Rock (2009), Buzón de naufragios (2012), Baladas para el ausente (2013) y Cenizas del bufón (2014). Coautor de: La novela del Tolima 1905-2005, bibliografía y reseñas (2008); Cien años de novela en el Tolima 1905-2005 (2011); y Cuentos del Tolima, antología crítica (2011). 
Laughter in the desert: el arte de la resurrección y sermones y prédicas del Cristo de Elqui [The Art of Resurrection and Sermons and Preaching of the Christ of Elqui]

\section{Abstract}

This article analyzes the carnivalesque aesthetic of the novel El arte de la resurreccion [The Art of the Resurrection] (2010) by Hernán Rivera Letelier, and the poetry books Sermones y prédicas del Cristo de Elqui [Sermons and Preaching of the Christ of Elqui] (1977) and Nuevos Sermones y prédicas del Cristo de Elqui [New Sermons and Preaching of the Christ of Elqui] (1979) by Nicanor Parra. These books are based on a real and eccentric preacher of the history of Chile: Domingo Zárate Vega, better known as "The Christ of Elqui". The article uses the concepts of Mijail Bajtín to explore laughter and madness as resources that generate a critical view of the misery of the nitrate miners in the Chilean desert, the military dictatorship of Augusto Pinochet and the killing of the Saint Mary Iquique School (21 December 1907).

Key words: Christ of Elqui, antipoetry, Chilean narrative, carnival, history.

\section{Un rire dans le désert: el arte de la resurrección}

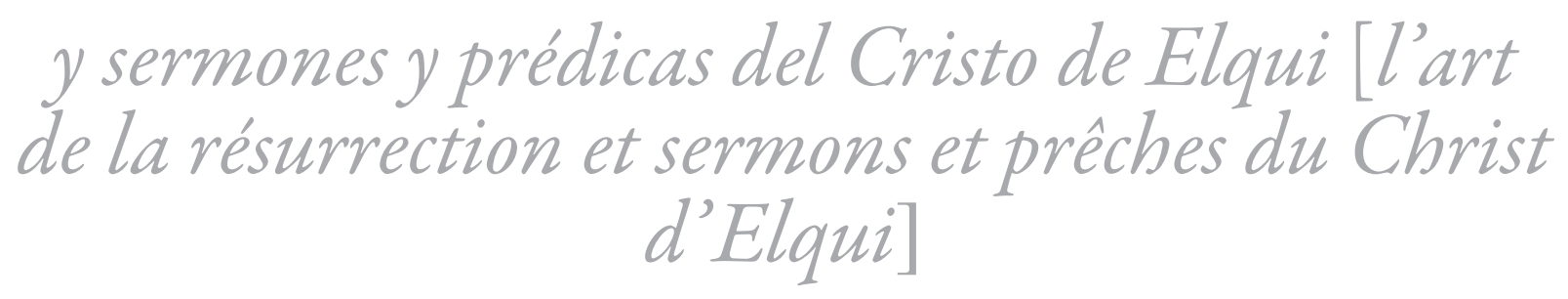

\section{Résumé}

Cet article de réflexion analyse la proposition carnavalesque du roman El arte de la resurrección [l'art de la résurrection] (2010), d'Hernán Rivera Letelier, et des recueils de poèmes Sermones y prédicas del Cristo de Elqui [Sermons et prêches du christ d'Elqui] (1977) et Nuevos sermones y prédicas del Cristo de Elqui [Nouveau Sermons et prêches du christ d'Elqui] (1979), de Nicanor Parra. Dans ces œuvres, le protagoniste est un prédicateur excentrique. Il s'agit d'un personnage réel dans l'histoire du Chili : Domingo Zárate Vega, mieux connu comme El Cristo de Elqui. Nous reprenons les théories de Mikhail Bakhtine pour étudier le rire et la folie comme ressources esthétiques générant une vision critique de la misère des mineurs des salpêtrières du désert chilien, la dictature militaire d'Augusto Pinochet et le massacre de l'École Sainte Marie d'Iquique (le 21 décembre 1907).

Mots clés: Christ d'Elqui, antipoésie, littérature chilienne, carnaval, histoire. 


\section{Preámbulo}

El poema XLV de Nuevos Sermones y prédicas del Cristo de Elqui (1979) señala: "A medida que vayan cayendo las hojas del calendario/ muchos cristos aparecerán en escena/ de esto no quepa la menor duda" (Parra, p. 25). Los pasos del chileno Domingo Zarate Vega (1898 1971), conocido como el Cristo de Elqui, se multiplican en las geografías eternas de la ficción. A este personaje carnavalesco que llevó sus plegarias a muchos australes ansiosos de sanar sus almas -desde la devoción o la risa- le llegó la resurrección por obra y gracia de la palabra mesiánica de Nicanor Parra y Hernán Rivera Letelier. Ambos autores se aseguraron de que el loco predicador se eternizara en la lírica, el teatro y la novela. El primero en salvarlo del olvido fue Nicanor Parra, quien en 1977 publicó Sermones y prédicas del Cristo de Elqui y luego en 1979 Nuevos Sermones y prédicas del Cristo de Elqui. El antipoeta llevó a las tablas en 1982 Sermones y prédicas del Cristo de Elqui con la compañía Teatro Pobre. Luego vendría Hernán Rivera Letelier, quien retomó al personaje en sus novelas $L a$ reina Isabel cantaba rancheras (1994), Los trenes se van al purgatorio (2000), Mi nombre es Malarrosa (2008) y El arte de la resurrección (2010). En las tres primeras, el Cristo de Elqui es una presencia secundaria y pintoresca en medio de la dura supervivencia de los mineros del desierto de Atacama. De unas cuantas páginas terminó en una obsesión que obligó a Hernán Rivera Letelier a dedicarle un espacio propio, justamente $E l$ arte de la resurrección, novela ganadora del Premio Alfaguara 2010.

El epígrafe inicial de El arte de la resurrección corresponde a estos versos de Sermones y prédicas del Cristo de Elqui: "N.S.J. no necesita presentación/ es conocido en el mundo entero/ basta recordar su gloriosa muerte en la cruz/ seguida de una resurrección no menos espectacular/ un aplauso para N.S.J." (Parra, citado por Rivera Letelier, 2010, p. 9). A través de esta indicación paratextual sobre el antecedente de la ficcionalización del Cristo de Elqui, el novelista insinúa que en la antipoesía y en la narrativa siempre será primordial la risa contra el poder. Los dos poemarios de Nicanor Parra y El arte de la resurrección usan el Cristo de Elqui como máscara perfecta para que la literatura hable de muertos, vidas miserables en las salitreras, destierros y traumas del pasado chileno: la Matanza de la Escuela Santa María de Iquique (21 de diciembre de 1907) y la dictadura militar de Augusto Pinochet (1973-1990).

\section{Los aspectos anteriores} dan cuenta de una propuesta carnavalesca que es necesario explorar, a partir de los plantea- mientos de Mijaíl Bajtín en La cultura popular en la Edad Media y el Renacimiento, el contexto de François Rabelais. El corpus de estudio está integrado por $E l$ arte de la resurrección, de Hernán Rivera Letelier, Sermones y prédicas del Cristo de Elqui y Nuevos Sermones y prédicas del Cristo de Elqui, de Nicanor Parra. Este artículo se estructura en cuatro momentos específicos: 1) Breve aproximación a la vigencia de la carnavalización literaria; 2) Nicanor Parra y la burla contra el poder; 3) el mesías paródico y la puta santa en El arte de la resurrección; 4) Apuntes finales.

Breve aproximación a la vigencia de la carnavalización literaria

En tiempos de "vida líquida” -como postula Zigmunt Bauman en varios de sus libroslas fiestas populares han trivializado sus ritos y simbologías al convertirse en fugaces objetos de consumo. Indiscriminadamente se ven masivos eventos de vacua diversión y poca crítica social a los que se bautizan como carnavales. ¿Dónde queda el espesor cultural y antropológico del carnaval al reducirlo al mero espectáculo del desfile, la sensualidad y la risa tonta sin resonancias que sacudan el status quo?

Necesario es volver a aquellas obras literarias donde el carnaval presenta una fuerza 
transgresora que atenta contra toda forma de autoridad. Como resalta Mijail Bajtín, "la cosmovisión carnavalesca y el sistema de imágenes grotescas siguen viviendo y trasmitiéndose únicamente en la tradición estética" (2002, p. 32). Esa tradición instaurada en la novela, gracias a François Rabelais en los libros de Gargantúa y Pantagruel, se reinventa en las propuestas literarias de quienes abandonan el lenguaje solemne y logran, a través del principio cómico, violentar normas que mantienen un orden cuya cara oculta es la barbarie. En el caso latinoamericano, la carnavalización permite recusar las historias patrias. ¿Para contar la versión no oficial del continente no recurrieron a elementos de la carnavalización Carlos Fuentes en La región más transparente (1958), Gabriel García Márquez en Cien años de soledad (1967), Guillermo Cabrera Infante en Tres tristes tigres (1967), Alejo Carpentier en Concierto Barroco (1974), Evelio José Rosero en La carroza de Bolivar (2012), entre otros?

La carnavalización hace que los textos literarios se nutran de las fuentes populares: refranes, imaginarios, bufones y locos cuyos discursos ponen en tela de juicio las injusticias del orden establecido. Toda estabilidad se ve sacudida por imágenes ambivalentes: muerte y vida, llanto y alegría, lo profano y lo sagrado en un mismo cuerpo. Las normas convencionales se quiebran cuando estalla el juego, la parodia, las permutaciones entre lo alto y lo bajo, las verdades del vino y del espíritu entregado a los excesos y a la risa aniquiladora del miedo. Dicha risa, transgresora y blasfematoria, apunta sus armas contra la historia oficial.

Nicanor Parra y la burla contra el poder

En medio de los centenarios que en 2014 se hicieron a importantes escritores fallecidos (Julio Cortázar y Octavio Paz), Nicanor Parra celebró el 5 de septiembre sus cien años de existencia. Es como si el elixir de la larga vida estuviera en la risa, sus artefactos visuales y antipoemas. Varios de ellos retoman como personajes seres bíblicos que también han burlado a la muerte: Jesús y Lázaro. En "El poeta y la muerte", ella llega ebria a la casa de un viejo poeta $y$, aunque intente tomarlo, él es quien la somete a su voluntad sexual.

La resistencia de Nicanor Parra a la desaparición física estuvo en contravía de los discursos oficiales en Chile en 2010: "Algunos que ya nos dejaron como es el caso de Vicente Huidobro o Pablo de Rokha o un gran antipoeta como es Nicanor Parra" (Piñera, citado por Ramírez, p. 9). El error del presidente Sebastián Piñera en plena inauguración de la Feria del Libro de la Plaza de Armas -Santiago, 23 de abril de 2010, es un ejemplo de la pobreza intelectual de buena parte de los mandatarios latinoamericanos, simuladores de cultura para mostrar una falsa sensibilidad estética. Nicanor Parra devolvió el favor al político cuando decidió ahorcarlo junto al resto de presidentes chilenos en la obra visual "El pago de Chile". Dicha obra, presentada en la Universidad Diego Portales en el marco del homenaje al antipoeta, fue motivo de censura al impedirse que las imágenes de la exposición se transmitieran en pantallas gigantes en plazas públicas de Santiago.

La obra de Nicanor Parra es incómoda a las élites de su país. Sus creaciones punzantes están libres de militancias. Por eso, en "El pago de Chile", aparecen ahorcados Salvador Allende y Augusto Pinochet, Sebastián Piñera y la actual presidenta Michel Bachellet, entre tantos otros mandatarios del siglo XIX al presente. La antipoesía, como lo advierte Osvaldo Ulloa Sánchez, "denuncia el absurdo, las incongruencias, las contradicciones e incluso injusticias políticas. Sin embargo, permanece en la denuncia sin ofrecer una alternativa, una posibilidad de salvación: es una poesía de la desesperanza" (2010, p. 7). A diferencia de Neruda, y su convicción en que el Comunis- 
mo y la lucha de clases podrían traer bienestar a los pueblos latinoamericanos, Nicanor Parra es escéptico. Mientras el Nobel chileno canta al Che Guevara en su poema "Tristeza en la muerte de un héroe", el antipoeta no conmemora en sus textos líricos a los grandes personajes de la historia, sino a seres marginales.

Para burlar la censura durante la dictadura militar chilena, Nicanor Parra da la voz poética al Cristo de Elqui, un hombre al que se perdonarían sus palabras por padecer delirio místico crónico. Sin embargo, más allá de la patología, la locura se convierte en un poderoso mecanismo de enunciación que "permite observar el mundo con una mirada diferente, no influida por el punto de vista normal" (Bajtín, 2002, p. 36). En medio de sus irreverencias, el loco puede expresar las más duras verdades que quizás otros callarían por temor o conveniencia.

Nicanor Parra, aparte de tomar como voz poética a un Cristo loco, acentúa el efecto paródico al ubicar al personaje en "un set de televisión, metonimia de la sociedad del espectáculo" (Morales, 2012, p. 167). Desde allí habla tanto en Sermones y prédicas del Cristo de Elqui como en Nuevos sermones y prédicas del Cristo de Elqui. Entre risas y aplausos, el Cristo chileno hace un recuento de su periplo vital.
El Cristo de Elqui cuenta a sus espectadores cómo, tras recibir un telegrama el 5 de febrero de 1927 donde se le anunciaba la muerte de su madre, dejó de ser maestro albañil para llevar la palabra de Dios por todo Chile. Refiere que, luego de veintidós años de prédica, deja su barba y sayal para ser un ciudadano más: "La penitencia ya se cumplió/ pronto me podrán ver/ nuevamente vestido de civil" (Parra, 1979a, p. 9). Antes de colgar su vestimenta de profeta, aprovecha la teleaudiencia para dar consejos sobre leyes de tránsito, cuidado de la sexualidad, uso de yerbas y la importancia de "no cortarle las alas a las gallinas" (Parra, 1979b, p. 5). A los niños advierte que él no es Papá Noel: "No me confundan con el Viejito Pascuero/ no me escriban pidiendo regalos" (Parra, 1979b, p. 13). Señala que oficia exorcismos pero no milagros de resucitar cadáveres, en tanto "el arte excelso de la resucitación/ es exclusividad del divino maestro" (Parra, 1979a, p. 21). Es católico ferviente y curiosamente dice: "Soy un libre pensador" (p. 44). El lector disfruta las gracias de este profeta lleno de contradicciones y simplezas. No obstante, llega el momento en que la parodia se politiza y descarga su índice acusador a través del poema LIII:

Y estas son las profecías del Cristo de Elqui pronto muy pronto vencerá la izquierda prepararse muchachos y los señores explotadores que se vayan amarrando los pantalones con rieles ahora le toca al pueblo claro que los conchenchos tratarán de impedirlo por todos los medios asesinato - dólares - ITT imposible señoras y señores acuérdense de estas palabras proféticas un socialista subirá al poder en mala hora me dirán ustedes eso yo no lo sé lo que sé bien es que suicidará cuando se vea solo y traicionado (Parra, 1979b, p. 38).

En un set de televisión de 1977, el Cristo de Elqui habla como si fuera 1949 y señala hechos de 1973 a través de sus "palabras proféticas” (Parra, 1979b, p. 38). ¿Una profecía que en vez del futuro mira el pasado? ¿El poeta vidente, según Rimbaud, no es quien avizora claves monstruosas de un futuro y las revela en sus versos? ¿A qué se debe el loco manejo del tiempo? En una propuesta carnavalesca, la literatura da licencias al loco para torcer la línea del tiempo, transgredir la cronología y dar saltos del pasado al futuro para insinuar qué traumas históricos habrán de repetirse. La aparente locura tiene el rostro doloroso de la lucidez: la toma de la Casa de la Moneda y la muerte de Salvador Allende no es un asunto del ayer, sino una herida abierta que seguirá doliendo más allá del fin de la dictadura militar de 
Augusto Pinochet (1990). Lejos de alinearse en una tendencia política o de señalar si era favorable o no la llegada al poder de Salvador Allende -"eso yo no lo sé” (p. 38)-, el antipoeta condensa en pocas líneas hechos históricos que entrañan vergüenza: dólares que están detrás del golpe militar (la injerencia de los Estados Unidos); un presidente traicionado por su hombre de confianza, el general Augusto Pinochet, a quien había nombrado comandante en jefe del ejército, veintidós días antes del trágico 11 de septiembre de 1973.

En medio de los consejos y curiosos sermones del Cristo de Elqui se habla también de los desaparecidos y desterrados que dejó el golpe de estado a Salvador Allende. Aunque el humor tuerza el cuello al lenguaje grandilocuente, la risa que provoca el Cristo de Elqui amortaja, es oscura, ambivalente. Detrás de los versos en apariencia jocosos de quien "se da a entender a estornudos" (Parra, 2010, p. 72), hay dolor por quienes padecen el exilio, esa "grieta imposible de cicatrizar impuesta entre un ser humano y su lugar natal, entre el yo y su verdadero hogar" (Said, 2005, p. 179). Contundente resulta el poema LVII:

\footnotetext{
Imposible entender a los chilenos los que se quedaron aquí no piensan en otra cosa que en irse “este país no sirve para nada” los
}

que se fueron sueñan con volver inútilmente porque no se puede madre mía que estás en el cielo santificado sea tu nombre déjalos regresar a la patria no permitas que mueran en el destierro (Parra, 1979b, p. 41).

El antipoema hace una digresión sobre la angustia de muchos chilenos porque su país ha dejado de ser plácida casa, útero o espacio simbólico donde se encuentran razones poderosas que motiven el orgullo nacional. Quienes aún habitan en su interior se sienten en un no lugar, quizás por el miedo, la violencia, las penurias económicas o el desencanto de percibir rotos los vínculos afectivos entre vecinos 0 compañeros de trabajo. Quienes se fueron de Chile por causas forzosas también se sienten en un no lugar en el país de asilo. Todo el tiempo piensan en retornar, en recuperar la cercanía y el amor de sus seres queridos. Aquí, el exilio es "una condición de abandono terminal" (Said, 2005, p. 179) y "nunca se puede superar su esencial tristeza" ( $p$. 179). Esa tristeza no es ajena al Cristo de Elqui. Él sabe que la patria está ligada a la idea de madre y por eso se dirige a la suya, imaginándola en el cielo, divina y poderosa, para que brinde a los desterrados el sueño del retorno: "santificado sea tu nombre/ déjalos regresar a la patria/ no permitas que mueran en el destierro" (Parra, 1979b, p.
58). Estos versos que retoman y transgreden expresiones de la liturgia católica son la mejor evidencia de que Nicanor Parra maneja con acierto la parodia cómica y la parodia seria. Esta última le permite insinuar su posición crítica frente al momento histórico de la escritura, haciendo uso de recursos estéticos que dan belleza a la creación literaria, sin caer en panfletos y tonos quejumbrosos.

\section{El mesías paródico y la puta santa en El arte de la resurrección}

Hernán Rivera Letelier (Talca, 1914) es una de las principales voces de la narrativa chilena contemporánea. Fue minero y esa experiencia de trabajar en salitreras del ardoroso desierto de Atacama le dotó de una sensibilidad especial e historias llevadas con acierto a la ficción a través de las novelas La reina Isabel cantaba rancheras (1994), Fantamorgana de amor con banda de música (1998), El fantasista (2006), La contadora de películas (2009), entre otras. El alto nivel de visibilidad de sus narraciones hace que el lenguaje esté cargado de calor, polvo y sol rabioso. Recrea con nitidez la árida vida de los mineros al norte de Chile. Cuando habla de las altas temperaturas y del viento pesado que pareciera aruñar, el lector rememora los relatos de Juan Rulfo donde el calor no 
es una simple descripción del narrador, sino una sensación inevitable.

En el marco de la propuesta estética de ficcionalización del desierto y de la existencia en las salitreras tiene lugar $\mathrm{El}$ arte de la resurrección (2010). Varios aspectos biográficos del Cristo de Elqui poetizados por Nicanor Parra son retomados por Hernán Rivera Letelier: devoción por la figura materna; recuerdos como maestro de construcción; prédicas a lo largo de Chile; advertencias y consejos que figuraban en sus folletos. Obviamente la imaginación del escritor chileno agrega anécdotas y ahonda en la conciencia del protagonista.

La mayor parte de la novela transcurre en la salitrera La Providencia, denominada popularmente como "La Piojo". Allí llega en 1942 el Cristo de Elqui bajo la pretensión de convencer a que se una a su labor pastoral una mujer llamada Magalena Mercado, "la prostituta que parecía hermanita de la caridad" (Rivera Letelier, 2010, p. 73). Ella apoya una huelga minera y fía sus servicios sexuales a los trabajadores de la compañía minera administrada por un norteamericano. Es profundamente devota y a donde va siempre lleva una estatua de la Virgen María. Al igual que el "Cristo chileno” (p. 45), ella es un personaje carnavalesco y funde lo sagrado

y lo profano:

\begin{abstract}
Magalena Mercado se desvistió con un ritmo y una lentitud estudiada, sabia, martirizante; lo hizo sin dejar de repetir en susurros la oración recién aprendida:
\end{abstract}

-Santo Dios, Santo inmortal, Santo Fuerte, Santo protector, líbranos de todo mal... -terminó de quitarse el vestido de tafetán violeta-... Verbo divino, Verbo eterno, Verbo salvador, líbranos, Jesús mío, de todo dolor... -se quitó la enagua de seda-... Si no puedo amar, que no odie... -se quitó el sostén- ... si bien no puedo hacer, que no haga mal... -se quitó los calzones flamígeros-... que en tu gracia santificante, Señor nuestro, nos guíes con tu luz... -los dejó izados como bandera de lujuria en una perilla de su catre de bronce-... Que así sea por siempre. Amén... -y tocó la campana. La tocó como si se tratara de uno más de sus feligreses (Rivera Letelier, 2010, p. 222).

Un campamento improvisado es burdel e iglesia al mismo tiempo. A quienes hacen la fila, ella anuncia con la campana el turno de la liturgia. Su cuerpo es salvación momentánea en medio de la lucha por la supervivencia. Se consagra a su labor con ritualidad. Aparte de sus oraciones y cultos católicos, su forma de ayudar al prójimo es entregando su cuerpo. Por el templo de su carne pasan el Cristo de Elqui, los pobres trabajadores que prometen pagarle cuando se levante la huelga, el anciano de los trasteos, jóvenes vírgenes, el dueño de la salitrera, visitantes de otras regiones e, incluso, los lisiados y dementes. Su cuerpo es escenario de carnaval, plaza pública sin jerarquías y prohibiciones. Todos pueden ir por un rato de sexo. Los mineros la adoran y le hacen un recibimiento masivo cuando ella vuelve a "La Piojo" tras un breve destierro. El retorno de la "puta beata” (Rivera Letelier, 2010, p. 214) es celebrado por una muchedumbre que le hace camino real, como rememorando la entrada de Jesús a Jerusalén.

El manejo de la entronización (de lo bajo a lo alto) y la desentronización (de lo alto a lo bajo) se evidencia en la propuesta carnavalesca de Hernán Rivera Letelier. Por su bondad y lealtad con la causa sindical a Magalena Mercado la eleva a la categoría de santa: “-iSi es como para canonizar a esta puta del carajo! ¿No le parece a usted, compañerito?" (Rivera Letelier, 2010 , p. 81). En cambio, al sacerdote del pueblo lo desciende a la categoría de soplón, debido a que usa el sacramento de la confesión para delatar secretos de los huelguistas. Se desnuda su doble moral, su forma de aprovecharse de la fe para abu- 
sar sexualmente de las niñas y el crimen de la madre de Magalena Mercado. Esa es la razón de que la hija siga al religioso al cambiar de parroquia, para recordarle con su presencia que él es su padre y violador. Se muestra al párroco como una criatura grotesca y repulsiva, cuyas acciones contradicen los sermones arrojados desde el púlpito. Come y bebe bien junto al dueño de la salitrera, sin importar el hambre de las familias de los huelguistas.

La casa de la prostituta y las tabernas se enaltecen en $E l$ arte de la resurrección. Lo profano se torna sagrado pues los excesos son la única posibilidad de la mayoría de habitantes de la salitrera para soportar la miseria y el calor que tornan lentas y agónicas las horas. En medio de la monotonía y el desamparo, la existencia de una santa ramera y la llegada de un loco predicador cobran sentido: "La bulliciosa alegría de ver por fin algo nuevo en el tedio infinito de la pampa" (Rivera Letelier, 2010, p. 59). Al igual que la prostituta devota, el cristo paródico convoca a las multitudes porque es "un Cristo pobre, sin un cobre, un Cristo perdonador, paciente y bueno, un Cristo chileno" (p. 45). Su locura es preferible a la grosera razón de los políticos que llegan al pueblo para conseguir votos y luego olvidar sus promesas:

$\mathrm{Su}$ ardua figura mesiáni- ca era engrandecida por el magnetismo de uno de los desiertos más penitenciales del planeta, su palabra era exaltada por el silencio astral de estas comarcas de castigo, y su evangelio, enaltecido por la desesperanza de sus habitantes, desesperanza de haber visto tantos redentores falsos recorriendo la pampa desde siempre -sobre todo en épocas de elecciones- cacareando la igualdad y la equidad para el obrero y su familia, ofreciendo hacer caer el maná desde la limpidez azul de este cielo inmisericorde y prometiendo el paraíso en la tierra, como si de una simple hectárea de campo se tratara. Por eso la devoción sincera de tantos de los nuestros, porque de verdad ansiábamos creer en la llegada de un mesías verdadero, un salvador que viniera a redimirnos de una vez por todas de tantas injusticias, de tantas infamias y degradaciones a que vivíamos sometidos a diario (Rivera Letelier, 2010, p. 52).

Los mineros prefieren a prostitutas y mesías locos, en vez de curas y líderes tradicionales de la política o de los sindicatos. $\mathrm{Al}$ respecto, es interesante una escena en la que detrás de un supuesto milagro del Cristo de Elqui -la multiplicación de los frijoles- había una explicación no ligada al orden espiritual. Sencillamente hubo comida para todos porque ese día los organizadores de la huelga se encontraban fuera de la salitrera: " $-j Y$ esas bestias son las que comen más que la sarna, comadre!" (Rivera Letelier, 2010, p. 70). En este aspecto existe una afinidad entre Hernán Rivera Letelier y Nicanor Parra: escepticismo sobre los discursos de redención social; un lenguaje incisivo para señalar las contradicciones entre las palabras y los hechos de representantes de la derecha y la izquierda. En la obra los personajes cuestionan los abusos de poder de sus explotadores y los incumplimientos de sus líderes comunistas. Significativo resulta que el final de la novela es el final de la huelga y los trabajadores repudian el pacto que firman los jerarcas del sindicato:

Algunos llegaron despotricando puño en alto en contra de esa manga de cabrones, hijos del carajo, que eran los dirigentes sindicales, que habían vendido el conflicto sin asco, pues qué otra cosa significaba que luego de tanta lucha, tanta miseria y tanto alboroto, apenas habían conseguido un tres y medio por ciento de aumento en el salario, ¡una mierda! (Rivera Letelier, 2010, p. 235).

La grosería no es el "insulto carente de sentido" (Bajtín, 2002, p. 27), sino la expresión 
de una lectura crítica del contexto. La grosería y la risa opacan el miedo para que la palabra fulmine la etiqueta y el protocolo, manifestando una dura verdad. Ambas permiten la aniquilación de normas, dan la voz al oprimido para expresar la frustración que le generan sus amos, sean los dueños de las salitreras o los líderes sindicales. Los dardos contra las actuaciones de representantes de la derecha y la izquierda están también en boca del Cristo de Elqui. De ahí que al estar rodeado por la multitud, lanza sus sermones contra dueños de las salitreras y "señores comunistas" (Rivera Letelier, 2010, p. 53). De estos últimos indica: "Se las daban de leídos y escribidos, y lo único que escriben es Viva Stalin en las paredes de los baños públicos, y lo único que leen es el diario en la mesa mientras almuerzan" ( $p$. 53). Se burla de los estereotipos, de quienes llevan boina y libros bajo el brazo para posar de intelectuales. Los trata de simuladores, de ignorantes que no han leído a los grandes pensadores del Marxismo y presumen de su sapiencia con frases cortas cargadas de lugares comunes. Incómoda es la presencia del Cristo de Elqui para los líderes sindicales de "La Piojo". El dueño de la salitrera, colérico por sus discursos, le hace propinar una golpiza y lo destierra de la zona, impidiéndole estar al lado de su Magalena.
El arte de la resurrección sacude al lector con sus risas y personajes ambivalentes que se debaten entre la santidad y la lujuria, las anécdotas de un Cristo chileno devoto del onanismo y del sexo con sus fieles, un personaje excéntrico que en momentos de "zozobra espiritual" (Rivera Letelier, 2010, p. 22) se saca los mocos para afianzar su fe. Él ha visto casi todo en su peregrinaje. A los oídos de este mesías paródico, como también a los de la puta santa, llegan los pesares de los seres sencillos, las tonterías de los niños y las insatisfacciones de mineros asediados por el hambre y el desierto. A muchos de ellos los atormentan los recuerdos de compañeros asesinados por el Estado. Una y otra vez la novela dirige su mirada al pasado para recusar la Historia: la matanza de cientos de huelguistas dedicados a la actividad salitrera que se encontraban departiendo en la escuela Santa María de Iquique un 21 de diciembre de 1907 , una navidad enlutada por las ametralladoras de una fuerza armada al mando del General Roberto Silva Renard, quien seguía las directrices del presidente Pedro Montt. Para el mandatario primaba el progreso sobre la humanidad; más que importar la suerte de los trabajadores, le obsesionaba la construcción de ferrocarriles y puertos.

La matanza de la Escuela Santa María de Iquique se desliza en la obra a través de las charlas de mineros miserables entregados a los excesos del cuerpo y del licor barato porque es lo único con lo que cuentan. $\mathrm{Su}$ júbilo en una taberna o en la casa de una prostituta es una máscara que esconde un rostro desencantado por las promesas del progreso, del Estado y falsos Mesías -distintos al pobre Cristo de Elqui- capaces "de convencer a un esquimal de que en el desierto de Atacama los iglúes eran mucho más confortables y que el hielo era de colores" ( $p$. 141).

\section{Apuntes finales}

La literatura no podía ser ajena a la tentación de escribir sobre uno de los personajes más excéntricos de Chile: Domingo Zárate Vega (Río Hurtado, 1898 - Santiago, 1971), un humilde campesino y obrero de construcción quien, tras la muerte de su católica madre, le rindió homenaje llevando la palabra de Dios por dos décadas bajo el nombre de Cristo de Elqui. Este "Cristo chileno" (Rivera Letelier, 2010, p. 45), presenció en su camino múltiples burlas y el reconocimiento de muchas mujeres y niños que lo veneraban. Sus palabras y folletos tenían amplia recepción en medio del calor y la rutina del desierto de Atacama. A muchos no les importó que lo hubieran encerrado en un manicomio de Santiago bajo el dictamen de 
sufrir delirio místico crónico. Su leyenda se fue repitiendo de boca en boca: curiosos milagros, voto de pobreza que avergonzaba a curas proclives al derroche, un cuerpo que aspiraba a la santidad sin negarse a los placeres de la vida sexual.

El Cristo de Elqui tenía prohibida la entrada a las iglesias por mandato de una carta firmada en 1931 por el obispo José María Cano. La literatura, esa morada para quienes deambulan de un lado a otro y son sometidos a la persecución, le ha dado un triple espacio en la ficción: El arte de la resurrección (2010) de Hernán Rivera Letelier, Sermones y prédicas del Cristo de Elqui (1977) y Nuevos sermones y prédicas del Cristo de Elqui (1979), de Nicanor Parra.

El escepticismo de Nicanor Parra hacia posibles figuras mesiánicas de la izquierda o la derecha no implica que la antipoesía cierre sus ojos al mundo, a sus crímenes y horrores. En ella hay una conciencia del tiempo y del espacio. No hay evasión ni silencio cómplice ante el horror. Detrás de la risa que provocan los discursos del Cristo de Elqui está la denuncia contra las implicaciones de la Toma de la Casa de la Moneda el 11 de septiembre de 1973 y la tragedia de los exiliados que contradijeron la dictadura militar de Augusto Pinochet. Como bien declara el autor chileno en uno de los poemas visuales de Artefactos: "El poeta es un simple locutor. / Él no responde por las malas noticias" (2010, p. 265). No da consuelos ni utopías, "aquí radica la diferencia con la poesía de Neruda, la cual sí entrega elementos esperanzadores y es optimista al creer en la salvación colectiva a través de la lucha política y social" (Ulloa Sánchez, 2010, p. 9).

La visión carnavalesca en $E l$ arte de la resurrección cuestiona el status quo y pone en la escena textual las pésimas condiciones de trabajo, salud y vivienda de los trabajadores del norte de Chile. Se emplean mecanismos simbólicos del carnaval que atacan toda autoridad, sin necesidad de caer en patetismos, lamentos y frases predecibles. Esa risa, que se desliza por el desierto de Atacama, es un arma poderosa para plantear cuestiones embarazosas: ¿Por qué si la minería ha sido la principal actividad económica de Chile, la zona desértica del norte del país parece fuera del progreso y de la "modernidad"? ¿De qué sirven las exportaciones y cifras de la minería si las condiciones de los obreros son lamentables? ¿Qué han obtenido los líderes de los sindicatos mineros cuando logran concertaciones con los empresarios?

El antipoeta Nicanor Parra y el novelista Hernán Rivera Le- telier carnavalizan la literatura para que la risa atente contra el poder y recuerde hechos traumáticos de Chile: la dictadura militar de Augusto Pinochet y La matanza de la Escuela Santa María de Iquique el 21 de diciembre de 1907. Las burlas contra las figuras de autoridad no implican la toma de un partido específico. Atacan por igual a ricos explotadores de una salitrera como a líderes sindicales cuyas acciones en beneficio propio van en contravía de sus discursos socialistas. A unos y a otros los degradan las obras estudiadas porque, tarde o temprano, terminan pareciéndose. Cómo no evocar un poema visual de Artefactos, de Nicanor Parra, en el cual hay una manifestación y una pancarta que dice: "la izquierda y la derecha unidas jamás serán vencidas" (2010, p. 278).

No sólo el poder político es afrentado en las creaciones estéticas de Nicanor Parra y Hernán Rivera Letelier, el poder eclesiástico no escapa al ajuste de cuentas. En El arte de la resurrección, el sacerdote de la Salitrera "La Piojo" se desentroniza cuando se muestra que, más allá de sus poses espirituales, lo movían en realidad los apetitos del estómago y de su vientre. Es visto como violador, traidor y asesino. El sacerdote de la novela es similar al de Nicanor Parra en "Desorden en el cielo": "Viviste entre los humanos/ del miedo de los 
enfermos" [...] Mientras los demás mordían un mísero pan de afrecho/ tú te llenabas la panza de carne y huevos frescos [...] La araña de la lujuria se multiplicó en tu cuerpo" (p. 48). He ahí la fuerza de una propuesta carvalesca en Nicanor Parra y Hernán Rivera Letelier que permite desarrollar "una visión del mundo, del hombre y de las relaciones humanas totalmente diferente, deliberadamente no-oficial, exterior a la Iglesia y al Estado" (Bajtín, 2002, p. 8).

\section{Referencias}

Bajtín, M. (2002). La cultura popular en la Edad Media y en el Renacimiento: el contexto de François Rabelais. Madrid: Alianza Editorial.

Morales, L. (2012). Nicanor Parra: el proyecto antipoético. Anales de literatura chilena, Año 13, (17), 147-167.

Parra, N. (1954). Poemas y antipoemas. Santiago de Chile: Editorial Nascimiento.

Parra, N. (2010). Parranda larga, antología poética. Santiago de Chile: Editorial Alfaguara.

Parra, N. (1979a). Sermones y prédicas del Cristo de Elqui. (Segunda edición). Valparaíso: Ediciones Ganymedes.

Parra, N. (1979b). Nuevos sermones y prédicas del Cristo de Elqui. Valparaíso: Ediciones Ganymedes.

Ramírez, N. (11 de junio de 2010). Los mejores "chascarros" de Piñera en sus primeros tres meses de gobierno. Emol. Chile. Recuperado de: http://www.emol.com/noticias/nacional/2010/06/11/418294/los-mejores-chascarros-de-pinera-en-sus-primeros-tres-meses-de-gobierno.html 


\section{la palabra}

Rivera Letelier, H. (2010). El arte de la resurrección. Santiago de Chile: Editorial Alfaguara.

Said, E. (2005). Reflexiones sobre el exilio, ensayos literarios y culturales. Barcelona: Editorial Debate.

Ulloa Sánchez, O. (2010). La antipoesía: la escéptica negación. Poesía chilena. Recuperado de: http:// www.poesias.cl/antipoesia.htm 